\title{
Effects of Heat Treatment on Microstructure and Properties of Inconel625 Alloy Blades Prepared by Selective Laser Melting
}

\author{
Mengting Zhang ${ }^{1,2}$, Xinghua Liang ${ }^{3}$, Xiaofeng Zhang ${ }^{2}$, Min Liu ${ }^{2}$, QingKun Chu ${ }^{2,4}$, Xi Zhou \\ ${ }^{1}$ School of Automotive Engineering, Liuzhou Vocational \& Technical College, Liuzhou, China; \\ ${ }^{2}$ Guangdong Institute of New Materials, National Engineering Laboratory for Modern Materials \\ Surface, Guangdong Academy of Science, Guangzhou, China \\ ${ }^{3}$ Guangxi Key Laboratory of Automobile Components and Vehicle Technology, Guangxi University of \\ Science \& technology, Liuzhou, China; \\ ${ }^{4}$ School of Materials and Energy, Guangdong University of Technology, Guangzhou, China \\ *E-mail: 475389617@,qq.com
}

Received: 26 September 2021 / Accepted: 29 October 2021 / Published: 6 December 2021

\begin{abstract}
Inconel625 alloy blades were prepared by selective laser melting (SLM). Optical microscope (OM), scanning electron microscope (SEM), electron backscatter diffraction (EBSD), energy dispersive spectrometer (EDS) analysis techniques were employed the microstructure and properties under asprepared and heat-treated conditions. The results show that the density of the as-prepared blades is as high as $99.9 \%$. The microscopic morphology exhibits obvious anisotropy with an angle of $67^{\circ}$ between two adjacent layers.MC granular phase and $\gamma$ phase are generated during solidification. The microstructures of blades at different positions are similar, which shows that the support design and production sequence during the preparation process have small effect on them. After heat treatment at $900^{\circ} \mathrm{C}$ for $4 \mathrm{~h}$, anisotropy with an angle of $67^{\circ}$ of as-prepared blades disappeared and new uniform crystal grains and Mo-rich phase area are discovered instead, and also with the improved corrosion resistance.
\end{abstract}

Keywords: SLM; Inconel625; blades; heat-treated

\section{FULL TEXT}

(C) 2022 The Authors. Published by ESG (www.electrochemsci.org). This article is an open access article distributed under the terms and conditions of the Creative Commons Attribution license (http://creativecommons.org/licenses/by/4.0/). 